\title{
The Cultural Factors in the MOOC Design in China from Hofstede's Cultural Dimensions
}

\author{
Xin Yang \\ School of Foreign Languages, Sichuan University of Arts and Science, Dazhou, Sichuan, China
}

\begin{abstract}
With their massiveness and openness, Moocs have become one of the most widespread and influential online learning forms, which leads to the fact that more and more designers with different cultural backgrounds are getting involved in the course design. As a result, the Mooc design such as the styles of the organization and presentation may correspondingly be influenced by cultural values of the designers, and then become barriers for learners. In order to locate the cultural influence reflected in the Mooc design in China, the introductory videos of three courses published on Coursera, which are designed by three well-known universities in China, are sampled for analysis from the aspects of power distance, individualism/collectivism and masculinity/femininity within the framework of Hofstede's cultural dimensions. The findings indicate that the cultural features of the high-power distance, collectivism and femininity have shown their influence on the designing of these courses.
\end{abstract}

Index Terms-Moocs in China, power distance, collectivism, femininity, Hofstede

\section{INTRODUCTION}

Moocs, as the name suggests, have developed into one of the most influential online forms of education. With their massiveness and openness, they have provided an interactive platform which has attracted millions of learners from different areas and of different ages, genders or professions, to complete their interested courses through the scaffolding provided by the instructors or other learners registered in the same course. As a result, more and more course designers and learners with different cultural backgrounds are communicating and exchanging information on the platform, and Moocs have inevitably evolved into a process of online teaching and learning which is based on intercultural communication. In the process, one influential factor should never be ignored, that is, culture, because Moocs themselves are cultural artefacts designed by people from different cultural backgrounds, and the designers may subconsciously embed cultural elements in the designing of Moocs (Callahan, 2005; Hargittai et al, 2006). It is said that culture can be a barrier to non-native speakers in online learning (Thompson, 2005; Welsh et al, 2013), while the key point is that many course designers may fail to notice their own cultural influence on the Mooc designs, including organizing and presenting styles.

Since the introduction of Moocs into China, it has increasingly drawn attention from researchers, teachers and students, especially among university students. The research about it mainly focuses on the aspects like participation, interaction, course building and assessment ( $\mathrm{Li}$, et al, 2017). Among these researches, the studies about learners' participation as a key index of Moocs' success has been the main stream. He et al (2014) adopted questionnaires to investigate the behavior and feelings of Chinese university students in Mooc study and found that they participated in and could insist on some courses because of the accessibility and their interest. Yang (2016) suggested that usability and internal motivation significantly influenced learners' insistence on learning. Till now, researchers have done a lot to focus on learners' experience and their behaviors mainly from the cognitive or psychological perspective, but few have paid attention to the cultural perspective with the Mooc design considered. Therefore, this paper is to analyze the cultural influence on course designing from power distance, individualism/collectivism, masculinity/femininity within the cultural dimensions proposed by Hofstede, to improve the intercultural awareness in Mooc design and promote the international development of Moocs in China.

\section{THEORETICAL FOUNDATION}

\section{A. Culture and Cultural Dimensions}

Broadly speaking, culture is the material and spiritual product that human beings have produced, inherited and developed, which is manifested in a nation's history, geography, customs, lifestyles, social norms and values. Till now, many philosophers, socialists, anthropologists and linguists have tried to define culture from different aspects, but there is hardly a unanimous definition of culture. The anthropologist Tylor (1871) mentioned in his Primitive Culture that culture was "the whole complex of traditional behavior which has been developed by the human race". Hofstede (1997) stated that culture is "the patterns of thinking, feeling and acting that people display as mental programs". His definition is partly echoed by Boldley, by whom culture is regarded as "what people think, what people do and what people produce" (Boldley, 2000). Though people have viewed culture differently, it can be found that there is something in 
common among those definitions: shared behavior and ideas or customs specific to human. Since culture can be learned and inherited from generation to generation, it can also exert an influence on people's understandings of and views toward the world, which are specifically reflected in their social behaviors, communications and cognitive processes.

In order to have a more complete and more concrete understanding of culture, experts have been working on the description and comparison of different cultures. Among them, the theory by Hofstede is the most influential one. Based on his investigation of the cultural values of the IBM staff working in 72 countries in 1960s and 1970s, Hofstede (1986, 1997, 2001) proposed five cultural dimensions, including power distance, uncertainty avoidance, individualism/collectivism, masculinity/femininity and long-term/short-term orientation. Power distance (PDI) refers to people's attitude toward the inequality of power distribution in the institutions and organizations within a country (Hofstede, 2001). People in society with a higher level of power distance index have stronger demand for social hierarchy while people in a lower power-distance society are more aware of the equity among people. Uncertainty avoidance (UAI) means "the extent to which people feel threatened by ambiguous situations, and have created beliefs and institutions to try to avoid these ambiguities" (Hofstede, 2001). A society with a higher UAI tends to emphasize the role of authority, seniority, social status and age in stabilizing the society and in avoiding uncertain factors. Individualism/collectivism (IDV) refers to the extent to which people in a society emphasize the importance of the collective interest. In a society with a higher IDV, people tend to give priority to their personal benefits. Masculinity/femininity (MAS) is defined as the masculine or feminine features reflected in a society. With a higher MAS, people tend to focus on competition, success and dictatorship. In contrast, with a lower MAS, people tend to be more modest, cooperative and caring. Long-term and short-term orientation (LTO) means the extent to which people in a society put emphasis on the future. A higher LTO culture tends to foster virtues of perseverance and thrift as well as the potential rewards in future.

According to Hofstede (1986), China is a big society which reflects a higher level of PDI, UAI, MAS, LTO and a lower level of IDV. Because of the influence from a long history of feudalism, Chinese have been used to the social system which strictly defines the hierarchy of the relationship among people, e.g., the relationship between the monarch and his subjects, that between father and son, and that between the master and his apprentices, all of which reflect the respect and obedience of the inferior to the superior. This system functions as a stabilization tool in a society and helps to reduce the uncertainty for people. Besides, it is believed that males are superior in society, and people long to be successful by working hard and being thrifty. In a culture with these features, teachers are regarded as an expert or authority in a certain area, whose position cannot be challenged, and students are simply supposed to be passive receivers of knowledge instead of questioning teachers' teachings. It is worth mentioning that students are expected to be diligent to achieve academic success for a more brilliant future.

\section{B. Cultural Concerns in Moocs}

Education, since it is a social behavior, is inevitably a reflection of culture. It is widely acknowledged that cultural differences have an influence on teaching and learning (Leidner and Kayworth, 2006; Edmundson, 2008). Vygotsky (1978) believed that culture is an important influential factor in one's learning and cognitive development, for its influence can always be found in the communication between the teacher and the students. Moocs are the production of the technological development in the modern education, and it is characterized by massiveness and openness, which means that instructors and learners from different countries and regions can encourage and support each other to finish studying knowledge through the interactive communication between the instructor and the learner, or among learners themselves. Therefore, cultural features may also exert an influence on the Mooc learning.

Hofstede's cultural dimensions have provided a new perspective to analyze the learners' behaviors in online learning. It is believed that in lower power distance, learners think that they can make progress on their own through learning the knowledge equally shared and distributed in society. In contrast, in higher power distance, learners expect to learn whatever they are taught to, for they suppose that knowledge is mainly from the authority like teachers. High uncertainty avoidance means that learners need specific guidelines and instructions in learning, while lower uncertainty avoidance expects learners to be more initiative, and to internalize their knowledge based on their own experience. In a more individualized society, learners have a strong self-responsibility for making their own choices in learning, while collectivism-oriented learners are more likely to listen to others' opinion, or make choices based on the whole group's preference. The learners from a masculine society tend to focus on their achievement or recognition in learning, while the learners from a feminine society choose the harmonious relationship among members in the learning community. Besides, learners with long-term orientation would work hard with a strong expectation for the future.

The cultural influence can be found in the two aspects of Mooc use and design. As for the cultural influence on Mooc use, the relevant research mainly has paid attention to its influence on instructing methods and learning results in Moocs. Most studies have identified the cultural factors in Mooc learning mainly by observing learners' behaviors, learning experiences or their evaluations of Moocs (Buholzer ect. 2018). It has been found that the completeness of the course on the platform of Moocs depended on learners' cultural background (Chew 2011; Eun 2009).

Based on the results found in those researches, it can be inferred that cultural influence may also be found in Mooc design. Therefore, it is of great value to investigate how cultural factors may exert influences on the designing of Moocs. Nisbett (2003) found that people's ways of organizing the visual and the textual information may vary with cultures. However, in contrast with the research about the cultural influence in Mooc use, there is very limited research about the 
cultural influence on Mooc design till now (Bayeck and Choi, 2018). Therefore, it is significant to investigate cultural factors in Mooc design, which can provide a new perspective for a better insight into Mooc design and the learning efficiency.

\section{The Study of Cultural Dimensions in Online Courses}

The website designers have already internalized their own national cultures, which may play a great part in the designing process of the websites in online courses. The study by Bansal and Zahedi (2006) indicated that the website images showed cultural content, and that there was consistency between the website designs and the designers' cultural backgrounds. Based on their analysis of images from 136 websites of 7countries with various cultural orientations, Bansal and Zahedi (2006) summarized the concrete cultural features of those websites from three dimensions in Hofstede's framework, including power distance, individualism/collectivism and masculinity/femininity.

For high power distance cultures, people in the website images usually have a formal pose, and they are dressed in a formal way. If there are a group of people, one person will be shown as the focus of attention. In low power distance cultures, there is no single person as the focus in the images and if there is a man in authority, he or she is mixed together with the background instead of appearing as the focus of attention and does not seem to be engaged in important tasks. If there are non-human objects, they are depicted as to be grand and in multiple in high-power distance cultures whereas in lower-power distance culture there is just a single object described.

As for masculinity/femininity, in a culture featured by masculinity, men are shown as authoritative figures with more serious appearance. Moreover, men are usually in formal clothes while women are in casual dresses. In a femininity-dominated culture, persons in the images are with more smiling faces; if there are women, they are more formally dressed and usually dressed in pink or other bright colors. Besides, the relationship like family members or friends will be emphasized and be revealed through their communications. The buildings and other objects described are usually the ones that are solid and many of them are together to create a somber atmosphere in a culture with a masculinity tendency, while in a femininity culture, the color of objects is brighter and the objects usually include cartoons, natural landscape, flowers or funny characters and artistic drawings.

In a culture of high-leveled individualism, when many people appear in the same image, the focus is only on one person. When a group of people are in the picture, they are not shown to communicate with each other, and they look at things from different angles. In a collectivism-characterized culture, when people are shown in groups, they observe objects from the same direction, and appear to be working on a common task. If there are non-human objects, things of a kind are shown in multiple representations.

\section{Methodology}

\section{A. Research Questions}

Hofstede's cultural dimensions were based on a wide range of data, and despite some criticism, it has been the most widely used model in cross-cultural analysis. Bansal and Zahedi (2006) investigated the cultural factors in web pictures from the three aspects of power distance, individualism/collectivism and masculinity/femininity, and summarized the visual cultural representation in them. Bayeck and Choi (2018) analyzed the Mooc videos and found that the designing of the Moocs reflected the designers' cultural background information. Given the fact that there is little research about the cultural factors in Mooc design in China, and with references to the two previous studies, this research is to analyze the cultural features in Chinses Moocs from power distance, individualism/collectivism and masculinity/femininity within the framework proposed by Hofstede to find out answers to the following two questions:

1. What are the features of these Moocs sampled?

2. Can cultural influences be found in these features?

\section{B. Procedure}

Since Coursera is one of the most influential Mooc platforms in the world, the sample courses in this study were all chosen from it. Moreover, since this study is a cross-cultural analysis, the samples should be those courses developed and taught by Chinses teachers in English, which are aimed at the English-speaking learners. Besides, in order to reduce the influence of the difference between arts and science, this study tried to cover the subjects in both arts and science. Based on these standards, the choices were narrowed down to the three sample courses, including Advanced Neurobiology by Peking University, Chinese Culture and Contemporary China by Nanking University and Mandarin Chinese 1: Chinese for Beginners by Shanghai Jiao Tong University. It is believed that the course introduction may influence learners' decisions to further their learning in these courses, so we chose the introductory videos of each course for analysis.

\section{Results}

\section{Power distance}

In the three videos of the course introduction, the instructors are all the focus of the camera, no matter whether they are sitting or standing while making the speech, which is just the exact description of the cultural feature in the high power-distance culture by Bansal and Zahedi (2006). Even if there are some background pictures behind or beside the 
instructors, the instructors are still foregrounded with other objects blurred. Just as is shown in Figure One, in the course of Advanced neurobiology by Peking University, it can be found that the course ware is being displayed on the screen of the computer beside the instructor, but the picture of the courseware is quite vague since it is not the focus. In Figure Two, in the course video of Chinese Culture and Contemporary China by Nanking University, the color of the background is plain and light in order to foreground the instructor. In the third picture, the course of Mandarin Chinese 1: Chinese for Beginners is characterized by the simple background with a focus on the formally-dressed instructor. In the three pictures, we can sense the authoritative positions of these instructors in delivering knowledge.

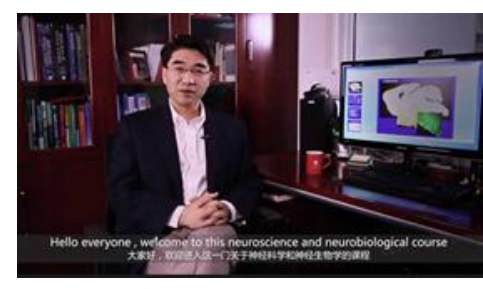

Figure 1

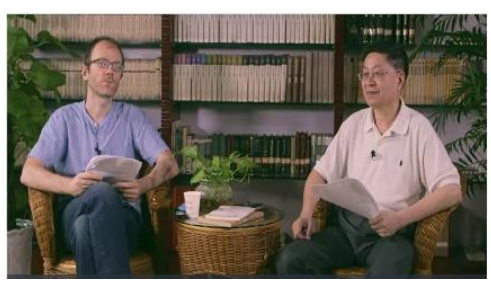

Figure 2

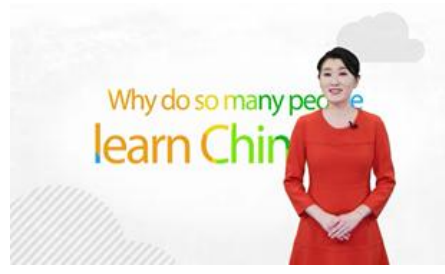

Figure 3

\section{Masculinity/femininity}

In the three introductory videos, the instructors are all behaving in a natural and relaxed manner with smiles on their faces. In Figure One, the main color is dark, and the male instructor is dressed informally, relaxed. In Figure Two, the two male instructors are also dressed in an informal way and communicating naturally. In Figure Three, the female instructor is in a formal dress with a bright color. Moreover, in this video, different colored artistic fonts are used to mark the course name, and many animations are designed, which indicates the femininity feature. All the information in these figures corresponds to the characteristics of the femininity-dominated culture described by Bansal and Zahedi (2006).

\section{Individualism/collectivism}

The obvious feature of collectivism is more than one person or one object appearing in the same shot, and all the people in the same frame show the same focus of their attention. In Figure Four, it can be found that the two people are working together, which is the scene that appears many times in the video. The teachers in the course team are shown a lot of times to coordinate with others to achieve the same goal. In this picture, the two persons are concentrating on the same task, which can be indicated by the directions of their eyesight. In Figure Five, when it comes to the course content, the relevant characters or the objects mentioned are diversified, and there are multiple buildings displayed and groups of people with the same focus of attention in the video. This is just the exemplification of collectivism in Chinese culture described by Hofstede. Similarly, in Figure Six, in the introductory video by Shanghai Jiao Tong University, the dynamic presentation of the course content is also accompanied by the appearance of multiple relevant objects at the same time.

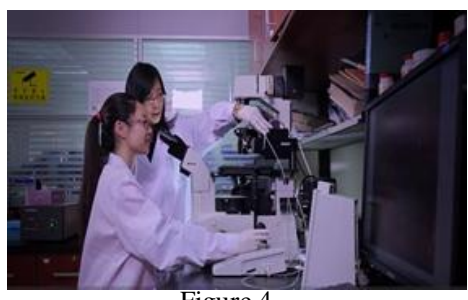

Figure 4

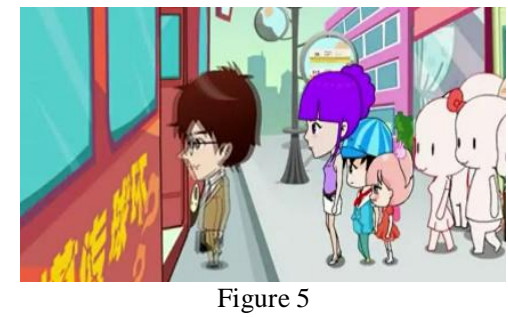

Figure 5

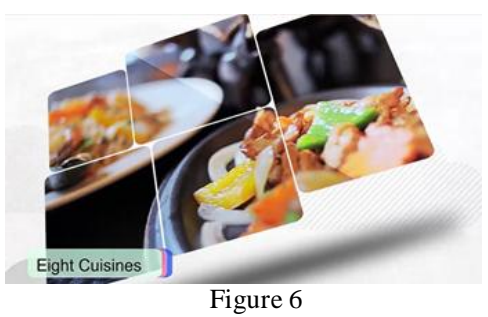

Figure 6

\section{DISCUSSIONS}

Based on the above analysis, it can be concluded that the three videos of the course introductions have embedded the features of the designers' cultural influence, which further proves that Moocs are the artistic works reflecting the national culture by Mooc designers. In consistency with the results found by Bayeck and Choi (2018) and by Hofstede (2001), these videos reflect the tendency of high-power distance and collectivism in Chinese culture. However, this study has found the femininity feature in these chosen videos, which is different from the previous related studies. The findings just echo what have been found by $\mathrm{Ku}$ and Lohr (2003), who claimed that the learning community of Chinese teachers and students showed obvious collectivism and femininity. It may be because of the influence from the traditional Confucian culture that the Chinese people have regarded modesty as their virtue, emphasizing the goodness of others, pursuing a happy and harmonious life, and lacking the spirit of independence, innovation and adventure. Therefore, it shows the cultural feature with more obvious feminization tendency.

As Mooc designers, it is necessary to pay attention to cultural features that are subconsciously embodied in Moocs, because the learners from different cultural backgrounds may feel cultural shock in the learning process and the learning efficiency might be decreased. Therefore, Mooc designing needs to consider the cultural influence from a 
comprehensive perspective. In other words, it is essential to make proper adjustments based on the cultural features of the target learners from the aspects of the course organization, the activity arrangements and the presenting styles of the videos. Learners from the low-power distance culture cannot adapt to the dull preaching of dogmas without any creativity, while learners with individualism cannot learn things passively because of their demand for manifesting their personality. Culture is a deeply-rooted value, so it is challenging to integrate the elements in target cultures into the course designing. It might as well be realized by embodying the music, images or signs from the target culture so that learners can adjust to the Mooc design and they can adhere to the Mooc learning to improve their learning efficiency.

\section{CONCLUSION}

The success of Mooc design can be influenced by many factors, and culture is among the most influential ones. Hofstede's framework has provided a new perspective for us to investigate the cultural factors in Mooc design, and it is proved again in this study that it is feasible to apply it in the similar analysis. This study, different from the previous ones, has discussed three cultural features in the Moocs designed in China. It is hoped that this study can provide some useful references for future studies about the designing and the internationalizing of Moocs produced in China.

The potential studies can be made by extending the investigation of cultural dimensions from the three to all the dimensions in Hofstede's framework, and by applying the multimodal analysis of the cultural elements to discuss the cultural features of the texts or the sounds. The exploration of the cultural features in Moocs can help designers to increase their awareness of cross-cultural communication, as a result of which, more Moocs with cross-cultural usability and learnability can be produced to meet learners' expectations of Moocs.

\section{REFERENCES}

[1] Bansal, G. \& F. Zahedi. (2006). Exploring cultural contents of website images. In Proceedings of the 12th Americas Conference on Information Systems (AMCIS). Atlanta: Association for Information Systems.

[2] Bayeck, R.Y. \& J. Choi. (2018). The influence of national culture on educational videos: The case of Moocs. International Review of Research in Open and Distributed Learning, 19(1), 186-201.

[3] Boldley, J. H. (2000). Cultural anthropology: Tribes, states, and the global system (3rd ed.). Mountain View, CA: Mayfield Publishing.

[4] Buholzer, F., R. Rietsche \& M. Söllner. (2018). Knowing what learners like - Developing a cultural sensitive peer assessment process in MOOCs. In: Multikonferenz. Wirtschaftsinformatik (MKWI). Lüneburg, Germany.

[5] Callahan, E. (2005). Interface design and culture. Annual Review of Information Science and Technology, 39(1), 255-310.

[6] Chew, Renee S.Y. (2011). Perceptions of online learning in an Australian university: Malaysian students' perspectives. Doctoral dissertation. Queensland University of Technology.

[7] Edmundson, A. (2008). Globalized e-learning: Cross-cultural dimensions. Berlin: Saarbrucken.

[8] Eun, Sook M. (2009). Cultural dimensions and online learning preferences of Asian students at Oklahoma State University in the United States. Doctoral dissertation. OKlahoma State University.

[9] Hargittai, E. \& S. Shafer. (2006). Differences in actual and perceived online skills: The role of gender. Social Science Quarterly, $87(2), 432-448$.

[10] He, C., Z. Wang \& X. Lv. (2014). Chinese college students' MOOCs learning experience: A survey study. Distance Education in China, 11, 42-49, 96.

[11] Hofstede, G. (1986). Cultural differences in teaching and learning. International Journal of Intercultural Relations, 10, 301-320.

[12] Hofstede, G. (1997). Cultures and organizations: Software of the mind. London: McGraw-Hill.

[13] Hofstede, G. (2001). Culture's consequences: Comparing values, behaviors, institutions, and organizations across nations (2nd ed.). Thousand Oaks. CA: Sage.

[14] Keesing, R.M. (1981). Cultural anthropology: A contemporary perspective. Holt, Rinehart and Winston.

[15] Ku, H. \& L. L. Lohr. (2003). A case study of Chinese students' attitude toward their first online learning experience. Education Technology Research and Development, 51(3), 94-102.

[16] Leidner, D. E. \& T. Kayworth. (2006). A review of culture in information systems research: Toward a theory of information technology culture conflict. MIS Quarterly, 30(2), 357-399.

[17] Li, X.Q., Y.Y. Chen \& X.J Gong. (2017). MOOCs in China: A review of literature, 2012-2016. In W.K. Will, et al (Eds.), New Ecology for Education - Communication X Learning. Singapore: Sringer, 21-33.

[18] Nisbett, R. E. (2003). The geography of thought: How Asians and Westerners think differently . . a and why. New York: Free Press.

[19] Thompson, L. \& H. Y. Ku. (2005). Chinese graduate students' experiences and attitudes toward online learning. Educational Media International, 42(1), 33-47.

[20] Tylor, E.B. (1871). Primitive Culture. London: J. Murray.

[21] Vygotsky, L. S. (1978). Mind in society: The development of higher psychological processes. Cambridge, MA: Harvard University Press.

[22] Welsh, D. H. \& M. Dragusin. (2013). The new generation of massive open online course (MOOCS) and entrepreneurship education. Small Business Institute ${ }^{\circledR}$ Journal, 9(1), 51-65.

[23] Yang, G. (2016). Factors affecting the continued use of Mooc user behavior. Open Education Research, 22(1), $100-111$. 
Xin Yang was born in Sichuan, China in 1981. She got her MA in Southwest University in China, majoring in Foreign Linguistics and Applied Linguistics. She is currently an associate professor in the School of Foreign Languages, Sichuan University of Arts and Science, Sichuan, China. Her research interests include Second Language Acquisition and Foreign Language Teaching. 